\title{
O que esta mulher está fazendo aqui? \\ A coragem de Alceste no Banquete de Platão*
}

\author{
What is this woman doing here? \\ Alcestis'courage in Plato's Symposium \\ Por: Fernanda Pio ${ }^{*}$ \\ Universidade de Brasília, Brasília, Brasil \\ Email: frrpio@gmai.com; \\ ORCID: 0000-0002-8614-9134 \\ Gabriele Cornelli** \\ Universidade de Brasília, Brasília, Brasil \\ Email: cornelli@unb.br \\ ORCID: 0000-0002-5588-7898
}

Fecha de recepción: 31/01/2019

Fecha de aprobación: 8/03/2019

Doi: $10.30972 /$ nvt.0143708

\section{Resumo}

Este artigo objetiva analisar a menção de Fedro à Alceste em seu discurso de elogio a Erōs no Banquete de Platão, buscando compreender a função deste exemplo, verificando a utilização da personagem como modelo relacionado à virtude da coragem (andreia), tipicamente relacionada à masculinidade, e a comparação com os personagens de Orfeu e Aquiles. No elogio, Fedro, após tratar da origem e das virtudes de Erōs, demonstra o poder do deus referenciando o amor na relação pederástica, exclusivamente homoerótica, entre erastēs, amante, e erōmenos, amado. Afirma que se um exército ou toda uma cidade fossem formados por erastai e erōmenoi esta seria a melhor maneira de convivência. Após afirmar que até mesmo as mulheres seriam

\footnotetext{
* Programa de Pós-Graduação em Metafísica, linha de pesquisa: Origens do Pensamento Ocidental

* Fernanda Pio é mestranda, bolsista pela Coordenação de Aperfeiçoamento de Pessoal de Nível Superior (CAPES), no programa de Pós-Graduação em Metafísica da Universidade de Brasília (UnB), sob orientação do Professor Doutor Gabriele Cornelli, na linha "Origens do Pensamento Ocidental" vinculada à Cátedra Unesco Archai. Pós-Graduada latu sensu em Filosofia (2019) e Bacharel em Direito (2016), ambos pela Pontifícia Universidade Católica de Minas Gerais (PUC Minas).

** Doctor en Filosofía por la Universidad Federal de San Pablo (Brasil). Docente de Filosofía Antigua en el Departamento de Filosofía, Universidad de Brasilia (Brasil). Director de la Cátedra UNESCO Archai "On the origins of Western Thought" Universidad de Brasilia (Brasil).
} 
capazes do maior ato de amor possível, morrer pelo amado ou amada, é inserido o exemplo de Alceste, que morreu no lugar de seu marido Admeto. Uma série de intérpretes identifica no texto o que seria a utilização de terminologia relacionada à pederastia, que pressupõe relação entre homens, para designar o relacionamento heterossexual da personagem, entendemos que isso não ocorre. O objetivo deste artigo é questionar a interpretação comum da inserção de Alceste na dinâmica da pederastia, se distanciando das implicações que esta leitura traria para a compreensão da função da personagem no discurso de Fedro. A análise será desenvolvida em dois momentos: primeiro, se verificará a menção da personagem como primeiro exemplo de performance de uma virtude tipicamente masculina no contexto de um discurso e de um diálogo que apresentam quase que exclusivamente referências à masculinidade; num segundo momento, se analisará a relação estabelecida por Fedro entre as personagens e as histórias de Alceste, Orfeu e Aquiles.

Palavras-chave: Platão, Banquete, Alceste, Gênero, Pederastia

\section{Abstract}

This article aims to address the mention of Alcestis in Phaedru's discourse praising Erōs at Plato's Simposyum, intending to comprehend the function of this example, considering the use of the character as a model related to the virtue of courage, andreia, typically related to masculinity, and the comparation with the characters Orpheus and Achilles. In his praise, after addressing origin and virtues of Erōs, Phaedrus demonstrates Erōs' power in pederastic relationships, that are exclusively homoerotic, between an erastēs, the lover, and an erōmenos, the beloved one, affirming that if an army or a city were composed only by erastai and erōmenoi, that would be the best manner of coexistence. After affirming that even women are capable of the supreme act of love, dying for the beloved, the example of Alcestis is introduced, she died so her husband Admetus could live. A series of commentators claim that the text uses a terminology related to pederasty referring to Alcestis heterosexual relationship, we understand that this doesn't occurs. The aim of this article is to question the interpretative possibility of Alcestis insertion on the dynamic 
of pederasty, distancing us of the implications that this insertion would bring to the comprehension of the character's presence at the discourse. Through the analysis of the text and the argumentative structure we propose an analysis of Alcestis participation on the praise in two parts. Firstly, verifying the mention of the character as the first example performing a typically manly virtue on a discourse, and a dialogue, that display almost exclusively references to masculinity. Secondly, analyzing the relation established by Phaedrus between the examples of Alcestis, Orpheus and Achilles.

Keywords: Plato, Alcestis, Symposium, Gender, Pederasty

\section{Cómo citar este artículo:}

APA: Pio, F. \& Cornelli, G., O (2019). O que esta mulher está fazendo aqui? A coragem de Alceste no Banquete de Platão. Nuevo Itinerario, 14 (1), 86-110. Recuperado de: (agregar dirección web)

\section{O Banquete platônico}

O Banquete, ainda que faça referência a um evento histórico, banquete oferecido por Agatão, em 416 aEC (Benardete; Bloom, 2001, p.181), para celebrar sua vitória como poeta trágico nas Lêneas, festival anual ateniense (Dover, 1980, p.9), se constitui de fato como obra de ficção, encentrada sobre os discursos que os simposiastas teriam proferido na ocasião. Temos indicação de que a narrativa do Banquete ocorre quinze anos após o evento que pretende rememorar (Rosen, 1987, p.7). No diálogo platônico, Apolodoro apresenta parte do relato que ouviu de Aristodemo, um dos presentes no evento, detalhes teriam sido confirmados por Apolodoro com o próprio Sócrates (173b).

Trata-se de um reconstrução propositalmente imperfeita "pelo uso dobrado do discurso indireto, Apolodoro conta o que Ihe contou Aristodemo, formando uma espécie de "telefone-sem-fio" (Franco, 2016, p.30), e por referências à incompletude do relato, em (173e) Apolodoro define como "relato aproximado" e "tentativa de 
reprodução" e em (178a) revela que a memória de Aristodemo não havia guardado tudo que cada um dos oradores disse e que, do que Aristodemo lhe disse, transmitiria o mais importante. Para Dover (1980, p.90), há marcas de uma vagueza que nos lembra de que a exata rememoração não é garantida.

Reunidos na casa de Agatão, deitados em divãs, após a refeição, os simposiastas deliberam que a reunião não seja marcada por excessos na bebida, seria uma reunião em que os discursos, bem regrados e pausados, constituiriam o cerne do evento. A ordem das falas foi estabelecida da esquerda para a direita, deste modo Sócrates seria o último a falar. No entanto, enquanto era aplaudido pelas palavras que acabara de proferir, entra na sala Alcibíades, completamente embriagado, e seu discurso constitui de fato um apêndice aos discursos anteriormente proferidos.

O Banquete é composto por discursos norteados pela proposta de homenagear o deus Erōs (177d), segundo Dover (1980, p.12) são descritos como "louvor" ou "encômio" e se relacionam a um gênero literário que tinha critérios definidos de formulação. Devia-se falar acerca do objeto do encômio: (1) características das quais é dotado: origem, força, beleza; (2) virtudes, como: coragem e honestidade; (3) antepassados; (4) conquistas, inclusive as que fez acontecer por intermédio de outros. Estes critérios, que perpassam todos os discursos do diálogo, serão encontrados especialmente nos de Fedro e Agatão.

\section{O discurso de Fedro}

Fedro é o primeiro simposiasta a falar, pois, dele teria sido a ideia de discursar sobre Erōs. Erixímaco, o menciona ao fazer a proposta do tema (177a) e em seguida se refere a ele como pai do discurso. (177d). Fedro inicia da seguinte maneira:

Erōs é um deus grandioso, extraordinário entre deuses e homens, por muitos motivos, entre os quais a origem não é o menor. Ser entre imortais, declaro, representa distinção ímpar (PI. Symp. 178a). ${ }^{1}$

Fedro define Erōs como deus grandioso, extraordinário entre deuses e homens, o imortal mais antigo, destaca sua origem e cita Hesíodo para homologar esta ideia,

\footnotetext{
${ }^{1}$ Todas as traduções do Banquete. A menos que não indicado diversamente, são de Shüller, D. (2009).
} 
afirmando que, após o nascimento do Caos, teriam surgido Terra e Erōs. Cita também Parmênides que afirmaria que antes de tudo a justiça teria ideado Erōs. (178b). Aqui, Fedro aborda três dos objetivos do encomio acima detectados por Dover: origem (1), características (3), e antepassados, "ancestrais de Erōs não existem" (178b) (1).

Como é o mais velho, é-nos causa dos maiores bens. Logo que se entra na adolescência, não sei dizer se existe benefício maior do que possuir um amante virtuoso, e, para o amante, do que um adolescente amado (Pl. Symp. 178c). ${ }^{2}$

Por ser o mais velho, Erōs, seria o causador dos maiores bens, Fedro trata de uma virtude de Erōs (2), e faz referência à pederastia.

O termo 'pederastia' designa o relacionamento erótico entre amante, homem adulto, denominado erastēs, e amado, adolescente do sexo masculino, erōmenos. Segundo Cantarella (2008, p.38-39), tal relacionamento era marcado por posições de atividade do adulto e de passividade do adolescente, do ponto de vista sexual, mas principalmente intelectual e moral, a 'assimetria' era aspecto essencial para aceitação social e cultural.

Fedro prossegue o discurso descrevendo como Erōs causará estes benefícios:

Erōs produzirá repulsa pela ação repugnante e apreço pelo comportamento honrável, onde quer que ela se manifeste. Sem isso, nem a polis nem o cidadão chegarão a elaborar obras eminentes e belas. Afirmo que o andra hostis erai, divulgada uma ação indigna sua ou sofrida por falta de virilidade, sem oferecer resistência, se caísse na vista do detentor de seus desejos, sentir-se-ia mais humilhado do que observado pelo pai, por amigos, por estranhos (PI. Symp.178d). ${ }^{3}$

Tal efeito se ampliado para uma cidade ou exército compostos por erastēs e erōmenos, seria a melhor forma de conviverem e absterem-se de ações reprováveis (178e). Identificamos uma preocupação do amante com o olhar do amado, diante de suas condutas, que seria mais importante do que o de qualquer outra pessoa. Hobbs (2000, p. 251-252) afirma que Fedro, não rejeita a dimensão da time, da honra, em detrimento do amor, mas a utiliza, como algo positivo, se manifestando no desejo de

\footnotetext{
2 Optamos por utilizar os termos "amante virtuoso" (Howatson; Sheffield, 2008) e "adolescente amado" (Franco, 2006) no lugar de erastēs e erômenos.

3 Traduzimos o termo philotimia por "apreço" ao invés de aplauso e "pelo comportamento honrável" (Howatson; Sheffield. 2008) ao invés de "à beleza".
} 
ser bem visto pelo amante ou pelo amado. O desejo de ser elogiado por muitos teria sido substituído pelo de ser elogiado por um.

Um erastēs preferiria muitas vezes morrer a ser visto pelo desejado a abandonar o posto ou a entregar as armas; o testemunho dos outros Ihe seria mais humilhante. Quanto a desamparar o desejado ou negar-Ihe socorro em perigo - ninguém seria tão indigno que o próprio Erōs não possa tornar, quanto à virtude, possuído pelo deus (PI. Symp.179a). ${ }^{4}$

Fedro insere no seu discurso sobre Erōs a temática da morte: usando referências militares, compara o ardor inspirado nos heróis aos efeitos de Erōs nos homens:

$\mathrm{Na}$ verdade, o que Homero afirmou, que "uma divindade inspira ardor a certos heróis", isso outorga Erōs de si mesmo aos amantes. Sem dúvida, só os amantes se dispõem a morrer uns pelos outros, não apenas os homens, mas até mesmo as mulheres (PI. Symp. 179b). ${ }^{5}$

Para Fedro, morrer pelo amado parece ser o ápice da experiência erótica.

O que se segue no discurso é o quarto critério elencado por Dover, a apresentação de conquistas de Erōs, como provas de seu argumento, Fedro traz exemplos de pessoas que com ações engrandeceram a reputação do deus. A primeira a ser apresentada é Alceste:

Alceste, filha de Pélias, fornece aos helenos prova convincente do meu argumento. Só ela consentiu em morrer pelo seu marido, embora o pai e a mãe dele ainda fossem vivos. Com a assistência de Erōs, ela os superou em afeto, fazendo-os parecer estranhos ao filho, parentes apenas de nome. A ação de Alceste foi aprovada como bela não só pelos homens, mas também pelos deuses. Embora muitos tenham praticado inúmeros atos belos, só a número reduzido os deuses concederam o prêmio de retornarem vivos das profundezas do Hades. Encantados com o feito dela, permitiram do Hades subir de novo a alma (PI. Symp.179b - 179c).

Para Benardete e Bloom (2001, p.82) a escolha de Alceste como exemplo é surpreendente pois ela performa o que eles definem como a prática mais masculina de todas: de fato, Fedro constrói o texto com ênfase na coragem (andreia), virtude comumente associada à masculinidade e à guerra, e curiosamente elenca como primeiro exemplo desta virtude uma mulher.

\footnotetext{
${ }^{4}$ Optamos pela tradução de (Franco, 2006) no trecho "tão indigno que o próprio Erōs não possa tornar, quanto à virtude possuído pelo deus.

5 Traduzimos "amantes" ao invés de erōntes e "não apenas os homens, mas até mesmo mulheres" (Franco, 2006), ao invés de "quer homens, quer mulheres" (Schüller, 2009).
} 
Alceste consentindo morrer pelo seu marido, movida por Erōs, se torna exemplo da manifestação das virtudes do deus através dos homens. Percebemos a relação entre amor e morte, aqui, desvinculada do ambiente militar. Fedro apresenta uma mulher como modelo a ser emulado, o que é raro, senão único no corpus platônico, segundo Hobbs (2000, p.248). Prossigamos com o discurso:

Está provado que os deuses estimam o empenho e a força de Erōs acima de tudo. Quanto a Orfeu, filho de Eagro, concederam-Ihe o regresso do Hades, mas sem alcançar seu objetivo. Mostraram-lhe só um espetro da esposa, que ele quis recuperar, mas não the concederam a própria mulher, por o considerarem um homem de alma fraca, um mero tocador de cítara. Não tendo coragem de morrer apegado a ela como Alceste, penetrou ardilosamente no Hades, vivo. O motivo da punição foi esse (PI. Symp. 179d). ${ }^{6}$

Ao que parece, para Fedro, o prêmio de retornar vivo do Hades, restrito a poucos, e concedido a Alceste, demonstra o apreço dos deuses à força de Erōs sob os humanos. Orfeu, também retorna do Hades após penetrar ardilosamente para buscar Eurídice. No entanto, por ter sido considerado um homem de alma fraca, um mero tocador de cítara, seu retorno não é um prêmio, mas uma condenação. Além de ser impedido de atingir seu objetivo, isto é, resgatar a amada da morte, é ele mesmo condenado a uma morte violenta por mãos de mulheres.

Segundo Franco, o termo traduzido por "homem de alma fraca" "permitiria também supor que Fedro considera Orfeu um efeminado, já que aqui o verbo estaria sendo usado num sentido pejorativo, em relação a um caráter sem firmeza, e não em seu sentido mais comum, como se referindo a pessoas de caráter doce" (Franco, 2006, p.115).

A comparação de Alceste e Orfeu poderia tanto funcionar como um indicativo do poder de Erōs promovendo uma virtude tipicamente masculina também em mulheres, quanto para inferiorizar ainda mais Orfeu com apelos à falta de masculinidade.

"Mulheres executaram a sentença de morte". (179e) A morte de Orfeu, segundo Benardete e Bloom (2001, p.83) teria sido ainda mais humilhante pois

6 Optamos pela tradução "homem de alma fraca" de (Franco, 2006), ao invés de "covarde" de Schüller (2009). 
executada por mulheres. Franco (2006, p. 123-124), pontua que haveriam versões diferentes acerca da morte de Orfeu: teria sido morto pelas mulheres da Trácia, por odiarem a infidelidade a Eurídice ou por Orfeu ter passado a menosprezar o sexo feminino, preferindo a companhia de rapazes; em outra versão, que remete à Ésquilo ${ }_{2}$ Orfeu é morto pelas Mênades, enviadas por Dionísio, que teria considerado a adoração de Orfeu a Apolo uma desfeita, já que tanto Orfeu quanto Dionísio eram trácios.

A versão esquiliana parece ser a mais provável, se entendemos a crítica de Fedro ao comportamento de Orfeu como uma desconsideração para com o deus Erōs análoga à que teve para com o deus Dioniso, em Bassarai. É possível que haja aí a intenção de evocar uma oposição entre Apolo e Dioniso, isto é, respectivamente entre a medida e a desmedida, para que a pensemos aplicada ao amor (Franco, 2006, p. 220).

O comportamento 'prudente', apolíneo, de Orfeu seria incompatível com a extrema virtude de Erōs que para Fedro, se traduz na voluntariedade de morrer por quem se ama.

Não Ihe tributaram honra como a Aquiles, filho de Tétis, que foi enviado às ilhas dos Felizes. Este, instruído pela mãe, sabia que deveria morrer se matasse Heitor, mas, se recuasse, poderia retornar à sua terra e viver por muitos anos; o herói elegeu corajosamente, no entanto, socorrer seu erastēs, Pátroclo. Aquiles, além de morrer, sacrificou-se por alguém que já estava morto (PI. Symp. 179e).

Um terceiro e último exemplo da generosidade da morte pelo amado é Aquiles, que mesmo sabendo de seu destino caso lutasse para vingar Pátroclo, decide voltar à batalha. Vejamos a narrativa da página platônica:

Esse ato provocou suprema a admiração nos deuses. Honra divina foi o resultado de tamanha dedicação. Que Aquiles tenha sido erastēs de Pátroclo, como quer Ésquilo, é um absurdo. Aquiles era mais belo do que Pátroclo, era o mais formoso de todos os heróis. Nem barba tinha. Era muito mais jovem pelo testemunho de Homero. O que na verdade os deuses mais apreciam é essa virtude, a que se forma em torno de Erōs. Cumulam de admiração, apreço e recompensas o erōmenos que se apega ao erastēs, bem mais do que o erastēs que se dedica ao adolescente. O erastēs é mais divino do que o preferido: do primeiro apoderou-se a divindade. Temos aí o motivo que induziu os deuses a preferirem Aquiles a Alceste, enviando-o às Ilhas dos Felizes. Pelo que foi exposto, afirmo que Erōs é o mais antigo dos deuses, o mais honrado, o mais 
poderoso para levar os homens à virtude e à felicidade nesta vida e depois da morte (Pl. Symp.180a-180b).

Nesta passagem, Fedro se esforça para estabelecer os papéis dentro da relação pederástica entre Aquiles e Pátroclo colocando Aquiles como o erōmenos, portanto o jovem e passivo e Pátroclo como o erastēs, o mais velho e ativo. Este é o motivo, segundo Fedro, que justifica a preferência dos deuses ao herói em detrimento de Alceste, os deuses apreciariam mais o sacrifício do amado em função do amante.

\section{Alceste}

Não podemos afirmar com precisão a que narrativa Platão se referia ao citar no diálogo Banquete a personagem Alceste, Dover (1980, p.93) menciona a tragédia Alceste de Eurípides mas afirma que Platão provavelmente se utilizou de uma versão mais antiga e simplificada da lenda.

A primeira referência a Alceste encontrada na literatura é na llíada de Homero:

Beba e Gláfiras e a bem fundada lolco: destes comandava onze naus o filho amado de Admeto, Eumelo, que para Admeto deu à luz a divina entre as mulheres, Alceste, a mais excelsa na beleza das filhas de Pélias (Hom. II. II, 712-714). ${ }^{8}$

Alceste é chamada de "divina entre as mulheres" quando é mencionado Eumelo, seu filho e de Admeto, comandante de algumas das naus que se preparavam para um ataque a Tróia.

Quanto à tragédia Alceste, é a mais antiga das obras conservadas de Eurípides, quarta e única restante da tetralogia composta por: As Cretenses, Alcméon em Psófis, Télefo e Alceste. Segundo Luschning e Roisman (2003, p.4), é uma peça pouco usual por ter elementos tanto da tragédia quanto da comédia, que encanta e desafia leitores e pesquisadores através dos anos

A tragédia narra a história da personagem Alceste que se oferece para morrer no lugar de seu esposo, o rei Admeto. Esta foi uma condição conseguida pelo deus Apolo, quando era servo de Admeto, para salvá-lo da morte. Apolo servia a um mortal

\footnotetext{
7 Traduzimos por "adolescente" ao invés de "jovenzinho", o termo paidika.

${ }^{8}$ Tradução de Lourenço. F (1950).
} 
como condenação por ter matado os Cíclopes, artífices do fogo de Zeus. Admeto viveria desde que alguém se dispusesse a morrer em seu lugar.

Dadas as condições para salvação de Admeto, o rei recorreu a seus amigos e até mesmo a seus pais que já estavam em idade avançada, mas não encontrou alguém disposto a se sacrificar por ele, apenas sua esposa.

A tragédia inicia com Apolo rememorando sua interferência em favor de Admeto, seguida da busca do rei por voluntários a morrerem em seu lugar. Já se retirando da casa de Admeto, Apolo encontra com a Morte, que viera para levar Alceste, o deus lamenta a tragédia iminente e anuncia que mesmo sendo infrutíferas suas tentativas de evitar ou postergar a morte de da esposa de Admeto, um homem poderoso a resgataria do Hades.

Por mais cruel que sejas, terás um dia que recuar: tão poderoso será o homem que virá à morada de Feres, enviado por Euristeu para trazer um carro de cavalos das terras de clima rigoroso da Trácia. Ao receber hospitalidade na casa de Admeto, há-de arrancar-te à força esta mulher. Assim, sem alcançar da minha parte reconhecimento algum, farás da mesma maneira o que pretendo e ser-me-às odiosa (E. Alc. 65-71). ${ }^{9}$

O Coro anuncia que a hora se aproxima, que Admeto já esgotou as alternativas possíveis, enchendo altares de todos os deuses com sacrifícios sangrentos para evitar a morte de Alceste, que, por sua vez é louvada por sua nobreza. "Então que ela saiba que, morrendo em glória, é de longe a mais nobre mulher debaixo do sol". (E. Alc. 150151)

\section{Exclama a Serva:}

Como não há-de ser a melhor? Quem o contradirá? Que terá de ser a mulher capaz de exceder? E como pode alguém demonstrar mais amor por um esposo do que oferecendo a vida por ele? (E. Alc. 152-155)

Alceste, nos braços de Admeto vislumbra seu destino:

Levam-me, levam-me, levam-me - não vês? - para a morada dos mortos. Sob o azul escuro das sobrancelhas, olha-me Hades, alado. Deixa-me estar. Que fazes? Largame. Que caminho sigo eu, desgraçada! (E.Alc. 259-262)

\footnotetext{
${ }^{9}$ Todas as traduções da Alceste são de Malça, A.N. \& Pulquério M.O. (1973), com algumas alterações menores.
} 
Lamenta os filhos que deixará órfãos, pede para que o esposo não contraia novas núpcias e condena a recusa dos pais de Admeto que não se dispuseram a morrer pelo filho. Alceste anuncia a Admeto e aos filhos o futuro orgulhoso de terem possuído a melhor das mulheres e das mães (E. Alc. 323-325). O que denota uma espécie de orgulho e até mesmo conforto no sacrifício. Alceste expira pela última vez, indicando a partida para o Hades.

Para Santos (2012) o embate envolto na tragédia é magnífico pois além de tratar do desejo de vencer a morte à custa do perecimento da vida alheia trata da voluntariedade de uma mulher de ceder sua vida "que por este gesto é comparada aos mais excelentes guerreiros" (Santos, 2012, p.187).

O retorno de Alceste, como previsto por Apolo, acontecerá através de Héracles, personagem que já havia descido ao Hades em um de seus doze trabalhos.

Héracles, chega à casa de Admeto que oculta o fato da morte da esposa, para hospedar o herói, alega que a morte foi na verdade de uma estrangeira ligada à sua casa. Mesmo assim Héracles insiste em partir, mas Admeto mantém a oferta.

O Coro:

E agora, franqueando a sua casa, com os olhos húmidos recebeu um hóspede, chorando a morte de sua querida esposa, que há pouco ocorreu no palácio. A nobreza é sempre impelida ao cumprimento do dever; nos homens de bem vive toda a sabedoria. A estes dedico a minha admiração e no meu coração permanece a confiança de que o ser humano, temente aos deuses, há-de ser bem sucedido (E. Alc. 591-597).

Enquanto Héracles desfrutava da hospitalidade de Admeto, ocorria, sem que o herói soubesse, o funeral de Alceste. Admeto e seu pai Feres discutem sobre a recusa de morrer no lugar do filho, Feres considera Admeto o responsável pela morte de Alceste e não reconhece o pretenso dever alegado por Admeto de morrer em seu lugar.

Feres: Partirei. Quem a vai sepultar és tu, o seu próprio assassino, e ainda hás-de prestar contas aos seus parentes: Acaso será um homem sem valor, se não vingar o sangue da irmã. Admeto: Oxalá pereças em breve, tu e aquela que contigo coabita. Sem descendência, apesar de terdes um filho, continuai a envelhecer da maneira que mereceis. Não suportarei mais a vossa presença debaixo do mesmo tecto; e se eu pudesse, pela voz dos arautos renunciar à casa paterna, renunciaria. Mas visto que 
tenho de suportar este mal presente, o melhor será ir colocar a morta na pira (E. Alc. 730 - 740).

Herácles, através de um criado toma conhecimento da morte de Alceste, que era sim estrangeira, mas também ama da casa.

Ó coração que tanto tens suportado, e tu, meu braço, mostrai agora que filho deu a Zeus a Tiríntia, nascida de Eléctrion, Alcmena. Preciso salvar a mulher que morreu há pouco e trazer de novo para esta casa Alceste, a fim de recompensar Admeto. Irei espiar a Morte, a senhora dos mortos de negro manto, e hei-de encontrá-la, penso eu, junto do túmulo, a beber o sangue das vítimas. E se eu precipitar o meu lugar de emboscada e apanhar, envolvê-la-ei com meus braços e não haverá ninguém capaz de libertar os seus flancos doloridos antes que me seja entregue a mulher. Mas se me falhar esta presa, se ela não se aproximar da oferenda sangrenta, descerei aos Infernos, às sombrias moradas de Core e do Senhor, e farei a minha súplica. Estou convencido de que tratei à luz do dia Alceste, para entregar nas mãos do hospedeiro que me recebeu em sua casa, e não me repeliu, embora ferido por pesada desgraça, e que, num requinte de nobreza me ocultou estes factos, por respeito para comigo. Quem, entre os Tessálios, é mais hospitaleiro? Quem entre os habitantes da Grécia? Nunca ele terá de dizer que usou um homem perverso de sua generosidade (E. Alc. 841-860).

Sem saber que o herói partia em busca de Alceste, Admeto lamenta sua sorte:

Amigos, a sorte de minha mulher é, em minha opinião, mais feliz do que a minha, embora pareça o contrário. Nenhuma dor a atingirá jamais e de muitos sofrimentos ela saiu gloriosa. Eu, porém, que já devia ter morrido, escapei ao destino para arrastar uma vida miserável; compreendo-o agora. Como poderei eu transpor a entrada desta casa? A quem dirigirei a palavra ou quem me saudará, que possa alegrar a minha chegada? Para onde me voltar? A solidão da minha casa expulsar-me-á, quando diante dos olhos eu tiver o leito vazio de minha mulher e as cadeiras em que se sentava, e sob o tecto um solo coberto de pó. E os meus filhos, lançando-se sob os meus joelhos, hão de chorar a mãe, enquanto os servos lamentarão a boa senhora que a casa perdeu. Eis o que se passará no interior da minha casa. Mas no exterior, os esponsais dos Tessálios e as reuniões das mulheres hão-se impelir-me de novo para o palácio; não suportarei ver as companheiras de minha mulher. E qualquer inimigo meu poderá dizer estas palavras: Vede como ele vive na vergonha, ele não ousou morrer, dando em troca aquela que desposou para escapar cobardamente ao Hades. Julgará ele, depois disto que é um homem? E ainda odeia os pais, por não ter querido morrer. Esta a fama que há de somar-se à minha desgraça. Que vantagem terei eu em viver, amigos, prejudicado na reputação e mergulhado na infelicidade? (E. Alc. 937960)

Héracles volta trazendo Alceste, coberta por um véu, irreconhecível a Admeto, e pede para que o rei a guarde até seu retorno, se, no entanto perecesse na tarefa que almejava cumprir, Admeto deveria ficar com a mulher. Admeto prontamente se 
recusa, mas é constrangido por Héracles e à contragosto aceita. A identidade de Alceste é então revelada:

Hércacles: Guarda-a, então, e dirás um dia que o filho de Zeus é um hóspede generoso. Olha para ela e vê se se parece alguma coisa com a tua mulher. E que a tua felicidade afaste a tristeza! Admeto: Ó deuses, que dizer! Inesperado prodígio! É a minha mulher que vejo aqui verdadeiramente? Ou é a alegria ilusória, mandada por um deus, que me faz delirar? (E. Alc. 1120-1124)

É mesmo Alceste, Héracles de emboscada agarrou e tomou Alceste da Morte. Um último detalhe nos é apresentado: Alceste retorna sem voz e só voltará a falar após purificações:

Não te é permitido ouvir a sua voz até que ela seja purificada da sua consagração aos deuses subterrâneos e vejas chegar o terceiro dia. Mas leva-a para dentro e continua, Admeto, a tratar os teus hóspedes com a piedade de um justo. Adeus! (E. Alc. 11441149)

Admeto agradece e promove comemorações e oferendas, termina a tragédia.

\section{O que esta mulher está fazendo aí?}

A relação de Fedro entre amor e morte é estabelecida através da virtude da coragem, o que haveria de mais apreciado pelos deuses. Todo o discurso se constrói em torno da exaltação da coragem, que relacionada ao amor teria sua manifestação mais contundente na voluntariedade daquele que ama de morrer pelo amado.

Nos chama atenção a apresentação de uma personagem feminina como exemplo desta virtude, para Guthrie $(1975$, p.381) a presença de Alceste é a característica mais notável do discurso. Pois, como observado, a fala de Fedro é marcada por homoerotismo, referências à pederastia, instituição exclusivamente composta por homens, e exemplos relacionados à guerra, em Atenas, ligada quase que puramente à masculinidade. As aparições de mulheres, no diálogo, como Diotima são presenças-ausências, segundo Renaut (2018, p.335), sempre apresentadas através da locução de um homem.

Finkelberg (1997) argumenta acerca da necessidade de se discutir esta questão: 
Ao meu ver, comentadores do Banquete ainda não deram uma resposta satisfatória a esta questão. Na sua edição de 1782, Friedrich August Wolf, partindo do pressuposto de que Alceste "ela mesma era erōmenos, não menos que Aquiles", tentou solucionar o problema propondo emendas ao Banquete 180b-4. Alguns editores posteriores seguiram-no nisso. Em 1875, porém, Rettig discorda da posição de Wolf1s, argumentando que a "inversão do relacionamento natural" no caso de Alceste contribui para a deliberada transformação do amor heterossexual em uma forma de pederastia. Finalmente, Kenneth Dover sugere em seu recente comentário que "Fedro pensa que Alceste está amando Admeto mas não que Admeto está amando Alceste." Me parece, no entanto, que só se pode resolver a dificuldade advinda do tratamento dado a Alceste no Banquete $179 \mathrm{~b} 4-180 \mathrm{~b} 5$ colocando a passagem num contexto mais amplo do pensamento Platônico (Finkelberg, 1997, p. 233-234).

Finkelberg (1997, p.232) afirma também que uma terminologia homossexual teria sido utilizada para descrever um relacionamento heterossexual entre Alceste e Admeto, os termos erastēs e erōmenos que caracterizam respectivamente o amante e o amado, passivo e ativo da relação pederástica. No mesmo sentido estão, Franco (2006, p.105) indicando que Alceste é considerada a amante (erastēs), palavra raramente usada no feminino e Schuller (2009, p.39, n23) afirma que mulheres tocadas por Erōs são erastēs.

Cooksey, que também destaca a 'estranheza' do exemplo, “apenas amantes estariam dispostos a morrer uns pelos outros, incredulamente até se o amante fosse uma mulher" (Cooksey, 2010, p.37), em breve comentário sobre este trecho afirma que apesar de incluir as mulheres, Fedro privilegia o poder moral da união entre homens, que coloca Aquiles como amado, e por isso superior, com o objetivo de estabelecer uma analogia da relação entre amado e amante com a relação entre humanos e deuses.

Quando à identificação de Alceste como amante, Howatson e Sheffield (2008, p.11, n51) não entendem que haveria uma utilização da terminologia pederástica para caracterizar o relacionamento de Alceste, afirmam de maneira semelhante a Dover, que a pressuposição numa relação pederástica era de que apenas o amante sentia desejo sexual, e que Fedro estaria sugerindo, neste caso, que a motivação de Alceste se relacionava a um amor sexual, portanto não comparável ao amor do adolescente amado.

Temos delineados dois pontos de destaque ressaltados pelos comentadores citados: a hipótese da utilização de uma terminologia específica da relação 
pederástica, portanto, homoerótica, a uma relação heterossexual, de maneira ainda mais curiosa, colocando uma mulher no polo ativo da relação, quando compara Alceste e Aquiles. E o segundo ponto, que trata da utilização de Alceste, uma mulher, como exemplo num contexto predominantemente masculino, vinculada a uma virtude tipicamente masculina, sendo comparada a um herói, Aquiles.

Dentre os comentadores que identificam como algo presente no texto a caracterização de Alceste como erastēs de Admeto, nos termos da pederastia, nos apresentou Finkelberg que, alguns propuseram emendas ao texto e argumentos de que Fedro estaria invertendo o 'relacionamento natural' e transformando o relacionamento heterossexual em uma espécie de pederastia. Franco e Schuller também admitem a caracterização, mas não tratam diretamente da questão.

Todavia, não nos parece necessário promover emendas ao texto e nem ou admitir que Alceste teria sido inserida numa relação pederástica ou até mesmo considerada erastēs.

Acreditamos que seja importante voltar com cuidado ao texto platônico, com a intenção de dirimirmos melhor esta questão:

$\mathrm{Na}$ verdade, o que Homero afirmou, que "uma divindade inspira ardor a certos heróis", isso outorga Erōs de si mesmo aos amantes. Sem dúvida, só os amantes se dispõem a morrer uns pelos outros, não apenas os homens, mas até mesmo as mulheres (Pl. Symp. 179b). ${ }^{10}$

Aqui, Fedro prepara seu discurso para inserir o exemplo de Alceste. Até este momento as referências são específicas à pederastia e a situações relacionadas à vida do homem na polis, neste trecho, se utiliza do exemplo do ardor provocado por deuses em heróis, o que está alinhado com o discurso até esse ponto, para explicar a maneira que Erōs age nos que amam, no entanto, ele generaliza a questão do ponto de vista de gênero, e afirma que "os que amam", os erōntes, podem ser tanto homens quanto mulheres.

Deste modo, este trecho não parece inserir o relacionamento heterossexual numa dinâmica pederástica, como muitos comentadores acabam por assumir. Mas

\footnotetext{
10 Traduzimos "amantes" ao invés de erōntes e "não apenas os homens, mas até mesmo mulheres" (Franco, 2006), ao invés de "quer homens, quer mulheres" (Schüller, 2009).
} 
parece querer alargar o argumento, para demostrar que a influência de Erōs pode exceder o âmbito específico da pederastia, utilizado até aquele ponto, como será observado com os exemplos de Alceste e de Orfeu, ambos em relacionamentos heterossexuais.

Quando Alceste é compreendida como estranha à dinâmica da pederastia, e ainda assim 'a que ama', resta o estranhamento da inserção de uma mulher num contexto exclusivamente masculino, mas desaparece, a nosso ver, um problema que como vimos foi enfrentado com muita dificuldade pela crítica, aquele de uma aparente equalização do relacionamento hetero e homoerótico no discurso, ou até mesmo uma 'inversão' do relacionamento heterossexual.

Nossa interpretação converge com a de Franco (2006, p.100) de que a inclusão de mulheres no argumento, "e não apenas os homens, mas até mesmo as mulheres" (179b), objetiva demonstrar a 'hiperpotência de Erōs'.

Tratemos agora do segundo ponto, a performance de uma virtude tipicamente vinculada à masculinidade, a coragem (andreia), por Alceste, e a comparação de sua performance com a de Aquiles sob a ótica do poder de Erōs.

\section{A coragem como uma virtude masculina}

É marcante no discurso de Fedro a exaltação da virtude da coragem (andreia). A afirmação presente nas leituras apresentadas de que seria surpreendente a presença de Alceste, se relaciona em grande medida à percepção da coragem como virtude masculina na Grécia clássica.

Segundo Hobbs $(2000$, p.68) a visão tradicional, à qual dão voz Homero e a tragédia grega em geral ${ }_{L}$ é de que algumas virtudes são masculinas e outras femininas e que um homem virtuoso necessariamente apresentaria características diferentes das de uma mulher virtuosa. Neste sentido, as noções de masculinidade e coragem parecem estar 'inextrincavelmente entrelaçadas'.

No diálogo platônico Mênon, ao ser interpelado por Sócrates acerca da natureza da virtude, a personagem Mênon nos dá indícios dessa visão: 
Mas não é difícil dizer, Sócrates. Em primeiro lugar, se queres <que eu diga qual é> a virtude do homem, é fácil <dizer> que é esta a virtude do homem: ser xaáz de gerir as coisas da cidade, e, no exercício dessa gestão, fazer bem aos amigos e mal aos inimigos e guardar-se ele próprio de sobrer coisa parecida (PI. Men.71e). ${ }^{11}$

No discurso de Fedro, como observado anteriormente, a utilização de Alceste como exemplo de coragem deu força ao argumento de Fedro, estratégia que dependeu exatamente da existência de uma visão tradicional de que a virtude da coragem é vinculada à masculinidade. Segundo Renaut (2018, p.335), Platão, no decorrer de suas obras, apresenta tradições sociais e políticas ligadas à mulher, interrogando seus fundamentos. No mesmo sentido Hobbs destaca:

A discussão sobre o homem e mulher virtuosos é substituída pela discussão acerca do humano virtuoso: gênero é simplesmente irrelevante para considerações éticas. Sócrates, então, acredito que seja o primeiro grego do qual temos registro a questionar explicitamente o que é, por exemplo, que deve ser exaltado na ocasião em que um homem luta em uma batalha. Ele certamente é o primeiro grego do qual temos registro que explicitamente alega que o que deve ser exaltado é simplesmente a coragem do homem, e além disso, que essa coragem poderia, em teoria, ser demonstrada da mesma maneira por uma mulher, mesmo que ela tenha menos oportunidades na prática. O fato de que a coragem é determinada como "masculina", em outras palavras, é simplesmente resultado de contingência histórica (Hobbs, A, 2000, p. 73).

Disso temos elementos na resposta de Sócrates a Mênon, acerca da virtude do homem e da mulher. Na sequência da fala acima apresentada, Sócrates desafia a definição de Mênon sugerindo que a virtude não se diferencia pelo gênero como a saúde que não se diferencia se o indivíduo for homem ou mulher:

Mas é só a propósito da virtudo que te parece ser assim, Mênon: que a virtude do homem é diferente da virtude da mulher, e da dos outros? Ou passa-se a mesma coisa também com a saúde, com o tamanho e com a força? Parece-te ser uma a saúde do homem, outra a da mulher? Ou por toda parte é o mesmo caráter, se realmente for saúde, quer esteja no homem quer esteja em quem quer que seja? (PI. Men. 72d-e)

Por fim, Sócrates afirma sobre o exemplo de Ménon:

Não disseste que a virtude do homem é bem administrar a cidade, e que a da mulher <é bem administrar> a casa? (...) Será então que é possível bem administrar, seja a cidade, seja a casa, seja qualquer outra coisa, não administrando de maneira

\footnotetext{
${ }^{11}$ Traduções do Mênon são de Iglesias. M. (2001).
} 
prudente e justa? (...) Então, não é verdade? Se realmente administram de maneira justa e prudente, é por meio da justiça e da prudência que administração. (...) Logo, das mesmas coisas ambos precisam, tanto a mulher quanto o homem, se realmente devem ser bons: da justiça e da prudência. (...), mas, a criança e o ancião? Será que sendo intemperantes e injustos poderão jamais ser bons? (...) Logo, todos os seres humanos, é pela mesma maneira que são bons; pois é vindo a ter as mesmas coisas que se tornam bons. (...) Não seriam bons pela mesma maneira, não é mesmo? Se não fosse a mesma virtude que pertencesse a eles (PI. Men. 73a-c).

Há um exercício de Sócrates na busca por revelar a virtude como algo independente de particularidades do agente, como o gênero. No caso do discurso de Fedro, temos inclusive, em comparação com Alceste, um exemplo masculino que carece da virtude da coragem.

Renaut afirma que:

O personagem de Alceste (179b-d) é testemunha da coragem que ela demonstrou ao se sacrificar por seu marido Admeto, enquanto que o personagem de Orfeu, para efeito de contraste, é acusado por Fedro de lhe faltar virilidade devido ao seu apego à vida e é condenado a ser morto pelas bacantes (179d-e) (Renaut, 2018, p.335).

O questionamento de valores não é, no entanto, objetivo principal do discurso de Fedro, mas foi utilizado para reforçar o argumento desenvolvido. Da mesma forma, no Ménon, mesmo abordando de maneira direta a questão da natureza das virtudes, para a qual Platão apresenta uma espécie de neutralidade de gênero, o faz como forma de compreender a natureza das virtudes e não como temática principal.

Neste sentido temos a perspectiva de Renaut, acerca da condição da mulher, agora tratando da República, afirma que a emancipação da condição feminina "depende de uma concepção da justiça funcional e hierarquizada, e não de uma consideração do caráter cultural da dominação masculina" (Renaut, 2018, p.340), Hobbs (2007, p.268) destaca a utilização de argumentos e imagens que contradizem elementos predominantes na cultura como ferramentas pedagógicas, por serem surpreendentes e provocadoras.

No caso específico do discurso de Fedro, Platão desafia a tradição que vincula a virtude da coragem à masculinidade, nos parece coerente a hipótese de que o faz, neste contexto, para potencializar seu elogio a Erōs. O exemplo de Alceste questiona a perspectiva tradicional, e este é um elemento que reforça o argumento principal. Nos 


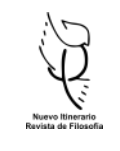

Pio, F. \& Cornelli, G., O

resta agora analisar a parte final que compara a personagem feminina a dois personagens masculinos

\section{A mulher o músico e o herói}

Após o exemplo de Alceste, temos o de Orfeu que é articulado em contraposição com o dela. Orfeu é considerado um homem de 'alma fraca' e o termo utilizado, segundo Franco (2006, p.115), pode significar também 'afeminado', a covardia de Orfeu não teria sido uma qualquer, mas a de um mortal que recusa a pretensão do deus de incendiar seu coração tornando-o um amante. Diferente de Alceste, Orfeu não teve coragem de morrer pela amada.

O terceiro exemplo, articulado primeiramente em relação a Orfeu e depois a Alceste $_{L}$ é o de Aquiles. Orfeu e Alceste não teriam sido tributados de honras como Aquiles, que, sendo erōmenos de Pátroclo, morreu por alguém que já estava morto.

Temos dois pontos que diferem a morte de Alceste da de Aquiles. Primeiro que Alceste morreu no lugar de Admeto, para que ele pudesse permanecer vivo e Aquiles, por Pátroclo que já estava morto. E segundo, por ser o amado, Aquiles executou o que os deuses mais apreciam que é a coragem de morrer, e além disso, morrer não estando possuído pela divindade.

O que na verdade os deuses mais apreciam é essa virtude, a que se forma em torno de Erōs. Cumulam de admiração, apreço e recompensas o erōmenos que se apega ao erastēs, bem mais do que o erastēs que se dedica ao adolescente. O erastēs é mais divino do que o preferido: do primeiro apoderou-se a divindade. Temos aí o motivo que induziu os deuses a preferirem Aquiles a Alceste, enviando-o às Ilhas dos Felizes. (PI. Simp.180a - 180b) ${ }^{12}$

Tendo descartado a hipótese de Platão ter inserido nesta passagem uma mulher no contexto da pederastia nos resta verificar a natureza da comparação que levou, segundo Fedro, os deuses a preferirem Aquiles a Alceste.

Howatson e Sheffield (2008, p.11. n.51), afirmam que a utilização da palavra agapē, que traduz por "devotion", "devoção", coaduna com a pressuposição tradicional grega de que numa relação pederástica somente o amante sente desejo

\footnotetext{
${ }^{12}$ Traduzimos por "adolescente" ao invés de jovenzinho o termo paidika.
} 
sexual Erōs. O termo Erōs é anteriormente utilizado para se referir ao amor de Alceste por Admeto o que indicaria que Alceste seria sexualmente atraída, o que a diferencia de um erōmenos que em regra não teria desejo sexual pelo erastēs. Neste caso, Alceste e Aquiles não são comparados dentro da dinâmica pederástica mas no tipo de sentimento que nutrem por Admeto e Pátroclo, respectivamente. Vejamos como articulam a tradução deste trecho:

Althought the gods show particular honour to the kind of excellence that comes from passionate love, it is those cases where the beloved shows his devotion to his lover rather than the other way round that they appreciate and admire more and reward more generously, because a lover has a god within him and he is thus more akin to the divine than the beloved. This is why the gods paid more honour to Achilles than to Alcestis and sent him to the Isles of the Blest (180a-b, tradução de Howatson; Sheffield, 2008).

Além da diferença no que concerne à atração sexual que existiria por parte de Alceste mas não de Aquiles, eles se diferenciam também por Aquiles não estar possuído por Erōs, e Alceste sim, logo a virtude de Aquiles seria superior por ser a que se forma em torno de Erōs e não diretamente advinda dele.

Tal interpretação, nos parece coerente pois, se observamos a descrição de como o poder de Erōs se manifesta, veremos que no trecho em que se refere à exemplos no combate, Fedro cita apenas ações do amante em relação ao amado. Provavelmente indicando que na relação pederástica apenas o erastēs é possuído pela divindade.

Além disso, os exemplos da manifestação de Erōs são Alceste e Orfeu, amantes, um bem sucedido e o outro não, mas ambos fora da dinâmica da pederastia e Aquiles, um amado, que mesmo não possuído pela divindade, dignou-se da admiração dos deuses em razão do apreço maior que é atribuído por eles à virtude que se forma em torno do Erōs. O Erōs, portanto, presente na relação pederástica entre Pátroclo e Aquiles, possuindo Pátroclo, o erastēs, permitiu o surgimento da coragem em seu entorno, manifesta na conduta de Aquiles. ${ }^{13}$

\footnotetext{
${ }^{13} \mathrm{Na}$ fala de Alcibíades, ao relatar um episódio ocorrido em um combate, revela que viveu uma situação em que estava ferido, mas não foi abandonado por Sócrates, que salvou até suas armas. Alcebíades foi condecorado nesta ocasião, apesar de insistir para que o homenageado fosse Sócrates, a justificativa nos mostra que este apreço maior pela virtude do amado não seja exclusivo dos deuses, 105 Nuevo Itinerario: Amor, inspiración y logos en el pensamiento
} antiguo 
Dover (1980, p.93-95) afirma que fica claro em 180b que Fedro pensa em Alceste amando Admeto mas não em Admeto amando Alceste, também afirma que o respeito e a devoção do erōmenos ao erastēs é uma forma de adoração e que os deuses reagiriam favoravelmente $a$ isso.

Há que se refletir também se haveria realmente a possibilidade de Alceste ser comparada a Aquiles, mesmo que não amasse ou sentisse desejo sexual por Admeto, pois, no trecho em que Fedro revela o que há de mais apreciado pelos deuses, retoma utilização de exemplos no âmbito da pederastia.

Nos parece que a articulação do argumento de Fedro busca, como pontuado anteriormente, enaltecer, acima de qualquer outra, um tipo ideal de relação que seria, de maneira mais propícia, senão exclusivamente, desenvolvida no seio de uma relação pederástica, no sentido trazido por Cooksey (2010, p.37), de que Fedro privilegia o poder moral da união entre homens, que coloca Aquiles como amado, e por isso superior, com o objetivo de estabelecer uma analogia da relação entre amado e amante com a relação entre humanos e deuses.

Neste sentido, Alceste jamais poderia alcançar as honras de Aquiles, por não se inserir no contexto homoerótico pederástico.

\section{Conclusão}

Compreendendo o Banquete como obra de fiç̧ão encentrada em discursos de elogio a Erōs que teriam sido proferidos num banquete oferecido por Agatão em 416 aEC, pontuamos acerca das diversas menções à incompletude e imperfeita descrição dos diálogos e detivemos nossa atenção ao discurso de Fedro.

Observamos que o discurso foi dividido em momentos, Fedro inicialmente fala da origem de Erōs, como deus grandioso e de sua genealogia, antiquíssimo ao ponto de não possuir ancestrais. Na sequência ressalta, como consequência da grandiosidade do deus, a virtude de ser o causador dos maiores bens, exemplificando este ponto com referências à pederastia, que considera o maior benefício tanto para o amante quanto

vejamos: "Mas os generais, considerando minha posição social, entendiam que o condecorado deveria ser eu. Mais do que os generais, tu insististe em que o homenageado fosse eu e não tu." (PI. Symp. 220e) 
para o amado. Por último descreve quais benefícios o deus poderá causar entre os homens, identificando como manifestação suprema do amor, morrer pelo amado.

Neste ponto a questão central do artigo se apresenta com a utilização de Alceste como primeiro exemplo da manifestação suprema de Erōs nos homens. A menção de Alceste no contexto de um diálogo e um discurso marcados por referências à masculinidade, pederastia e guerra, desperta interesse dos intérpretes, que se dividem, em primeira instância, entre a afirmação de que Alceste e seu relacionamento com Admeto teriam sido caracterizados com termos da pederastia e a negação de que esta relação teria sido estabelecida.

Inserir uma mulher na dinâmica de uma relação pederástica, parece, para alguns, inadequado ao ponto de postularem por alterações no texto. Para outros Platão teria promovido uma "inversão do relacionamento natural", transformando amor heterossexual em uma forma de pederastia.

Não entendemos que Alceste teria sido relacionada à pederastia. Por este motivo, nos filiando à perspectiva de que a personagem não é inserida na dinâmica da pederastia, investigamos o que acreditamos serem pontos relevantes à compreensão de sua presença no discurso.

A questão da coragem ser tradicionalmente relacionada à masculinidade é um dos pontos que permite o efeito "surpresa" e o peso do exemplo de Alceste. Fedro se utiliza do questionamento de valores tradicionais para dar força a seu argumento acerca da hiperpotência de Erōs, constrói um argumento repleto de referências à masculinidade, exaltando uma virtude tradicionalmente masculina, e como primeiro exemplo traz uma mulher. Observamos que Platão se utiliza de exemplos em que questiona valores tradicionais como ferramentas pedagógicas, o fortalece o argumento de que a utilização de Alceste neste contexto não teria como objetivo maior a relativização das virtudes com relação ao sexo ou ao gênero, mas que é utilizado primordialmente, no âmbito do discurso, como subterfúgio para fortalecer o argumento principal acerca do poder de Erōs.

A comparação promovida entre os exemplos de Alceste, Orfeu e Aquiles ocorre primeiro na articulação do exemplo de Orfeu em relação a Alceste. Orfeu é colocado 
como exemplo de homem covarde, o fato de ser um músico é utilizado em tom pejorativo "mero tocador de cítara". Neste contexto, levando em conta a exaltação da coragem como virtude masculina e em comparação com Alceste, uma mulher que performa virilidade é ainda mais "inferiorizado", de maneira recíproca seu exemplo destaca ainda mais o efeito da menção à Alceste.

Quanto à comparação com o herói Aquiles, observamos um processo para delinear o que fará no final do discurso, o herói ser colocado em posição de superioridade em relação a Alceste. Uma diferença entre Alceste e Aquiles residiria na sugestão de Alceste nutrir atração sexual por seu marido Admeto, o que a diferenciaria de Aquiles que por ser erōmenos na relação com Pátroclo não nutriria este tipo de sentimento. Parece haver uma relação não muito clara entre atração sexual e possessão por Erōs, que é o segundo ponto que poderia diferenciar Aquiles e Alceste, Aquiles não estaria possuído pelo deus, Alceste (supomos que sim). Por ser o mais apreciado pelos deuses, a virtude formada em torno de Erōs, Aquiles seria superior.

Outro ponto, no entanto, nos direciona para mais uma possibilidade interpretativa: Fedro ao mencionar que os deuses reservam especial honra ao erōmenos que se apega ao erastēs, bem mais do que ao erastēs que se apega ao adolescente, volta a utilizar denominações de natureza pederástica, tal fato nos leva a concluir que, tais honras não estão acessíveis, a não ser num contexto de pederastia.

Alceste, portanto, não é inserida no contexto da pederastia, relacionamento privilegiado aos olhos de Fedro, e este, seria um ponto que a inferioriza em relação a Aquiles, mesmo tendo promovido ação semelhante à do herói.

Sua aparição no discurso contribui para o argumento da excepcionalidade de Erōs, através da menção à sua conduta como exemplo da manifestação de uma virtude tipicamente relacionada à masculinidade, manifestação que a coloca, inclusive na tragédia de Eurípides, em comparação com a excelência de um guerreiro, neste caso de Aquiles.

\section{Referências}


1. Benardete, S. \& Bloom, A. (2001). Plato. Plato's Symposium (translation and commentaries). Chicago: The University of Chicago Press.

2. Canterella, E; Lear, A. (2008). Images of ancient Greek pederasty: boys were their gods. New York: Routledge [Epub format].

3. Cooksey, T.L. (2010). Plato. Plato's Symposium: a readers guide. London: Continuum.

4. Dover, K.J. (1980). Plato. Symposium (Commentary). Ed. Cambridge: Cambridge University Press.

5. Edwards, T. W. C. (2010). Euripides. Alcestis of Euripides (translation). New York: Cambridge University Press.

6. Finkelberg, M. (1997). Plato's Language of Love and the Female. In. The Harvard Theological Review, Vol. 90, No. 3, pp. 231-261. Cambridge: Cambridge University Press.

7. Franco, I. (2006). O Sopro do Amor: um comentário ao discurso de Fedro no Banquete de Platão. Rio de Janeiro: Palimpsesto.

8. Foucault, M. (1984). História da Sexualidade II: O Uso dos Pazeres. Rio de Janeiro: Graal.

9. Gomes. E. R. Platão. Ménon (tradução e notas). Lisboa: Edições Colibri.

10. Guthrie. W.K.C. (1975). A History of Greek Philosophy. Vol. 4. Cambridge: Cambridge University Press.

11. Howatson. M.C; Sheffield. F.C.C. (2008). Plato. The Symposium. In: Cambridge Texts in the History of Philosophy. Cambridge: Cambridge University Press.

12. Hobbs, A. (2000). Plato and the hero: courage manliness, and the impersonal god. New York: Cambridge University Press.

13. Hobbs, A. (2007). Female Imagery in Plato. In: Plato's Symposium: Issues in Interpretation and Reception. Washington, DC: Center for Hellenic Studies.

14. Iglesias, M. (2001). Mênon (tradução). Platão. Rio de Janeiro: Ed. PUC-Rio, Edições Loyola.

15. Lourenço. F. (2005). Homero. Ilíada (tradução). Penguin Companhia. 
16. Lushning. C. A. E. \& Roisman. H.M. (2003) Alcestis (notes and commentary). Euripides. In: Oklahoma series in classical culture; v.29. Oklahoma: University of Oklahoma Press.

17. Malça, A. N; Pulquério, M. O. (1973). Eurípedes. Alceste. In: Alceste, Andrômaca, ĺon e Bacantes (tradução). Lisboa: Verbo.

18. Nunes. C. A. (2015). Homero. Ilíada (tradução). Rio de Janeiro: Nova Fronteira.

19. Renaut, O. (2018). Gênero. In: Cornelli: G e Lopes: Rodolffo. Platão (pp.331325). São Paulo: Paulus; Portugal: Imprensa da Universidade de Coimbra.

20. Rosen, S. (1987). Plato's Symposium. Yale University.

21. Sandford, S. (2010). Plato and sex. Cambridge: Polity Press.

22. Santos, F.B (2012). A cena de agon na Alceste de Eurípides, p. 172-189. In: Competência y cooperación de la antiga grecia a la actualidade. La Plata: FAHCE-UNLP.

23. Schuller, D. (2009). Platão. O Banquete (tradução, notas e comentários). Porto Alegre: L\&PM Pocket. 